\title{
Gephyrin Interacts with Dynein Light Chains 1 and 2, Components of Motor Protein Complexes
}

\author{
Jens C. Fuhrmann, ${ }^{1}$ Stefan Kins, ${ }^{1}$ Philippe Rostaing, ${ }^{2}$ Oussama El Far, ${ }^{1}$ Joachim Kirsch, ${ }^{1}$ Morgan Sheng, ${ }^{3}$ \\ Antoine Triller, ${ }^{2}$ Heinrich Betz, ${ }^{1}$ and Matthias Kneussel ${ }^{1}$ \\ ${ }_{1}^{1}$ Max-Planck-Institute for Brain Research, Department of Neurochemistry, D-60528 Frankfurt/Main, Germany, \\ ¿Laboratoire de Biologie Cellulaire de la Synapse, Institut National de la Santé et de la Recherche Médicale U497, Ecole \\ Normale Supérieure, 75005 Paris, France, and ${ }^{3}$ Center for Learning and Memory, Massachusetts Institute of Technology, \\ Cambridge, Massachusetts 02139
}

The clustering of glycine receptors and major subtypes of $\mathrm{GABA}_{\mathrm{A}}$ receptors at inhibitory synapses is mediated by the tubulin-binding protein gephyrin. In an attempt to identify additional components of inhibitory postsynaptic specializations, we performed a yeast two-hybrid screen using gephyrin as bait. Multiple positive clones encoded either the dynein light chain-1 (Dlc-1), also known as dynein LC8 and protein inhibitor of neuronal nitric oxide synthase, or its homolog Dlc-2. Dlc-1 protein bound efficiently to gephyrin in in vitro binding assays and colocalized with gephyrin during coexpression in HEK293 cells. The binding site for Dlc was mapped to a fragment of 63 amino acids within the central linker domain of gephyrin. In hippocampal neurons, endogenous Dlc protein was enriched at synaptic sites identified by synaptophysin and gephyrin immunostaining. Immunoelectron microscopy in spinal cord sections revealed Dlc immunoreactivity at the edges of postsynaptic differentiations, in close contact with cytoskeletal structures and at the periphery of the Golgi apparatus. Because Dlc-1 and Dlc-2 have been described as stoichiometric components of cytoplasmic dynein and myosin-Va complexes, our results suggest that motor proteins are involved in the subcellular localization of gephyrin.

Key words: gephyrin; cytoplasmic dynein; myosin-Va; Dlc-1; PIN; LC8; DIc-2; inhibitory synapse; motor protein
Efficient neurotransmission at chemical synapses requires a high local concentration of synaptic proteins, such as components of the neurotransmitter release machinery and postsynaptic receptors. At the molecular level, this high extent of synaptic specialization is thought to result from both targeted delivery of individual constituents and selective stabilization of correctly formed structures (Craig and Banker, 1994; Hirokawa et al., 1996; Burack et al., 2000). On the postsynaptic side, different proteins have been identified that mediate the synaptic clustering of distinct families of neurotransmitter receptors. Receptors for glutamate, the major excitatory neurotransmitter in the CNS, interact via their cytoplasmic $\mathrm{C}$-terminal regions with proteins containing one or more PDZ domains [named after their occurrence in PSD-95 (postsynaptic density-95), Drosophila Discs-large, and ZO-1 (zona occludens-1)] (Sheng and Pak, 2000). Several of these PDZ domain proteins are directly or indirectly interconnected, thus forming the core of the electron-dense structure visible in electron microscopic images and known as postsynaptic density (Ziff, 1997). At inhibitory synapses, receptors for either glycine or GABA colocalize with the postsynaptic scaffolding

\footnotetext{
Received Nov. 13, 2001; revised March 25, 2002; accepted April 10, 2002.

This work was funded by the Deutsche Forschungsgemeinschaft and Fonds der Chemischen Industrie. Jens Fuhrmann was supported by a predoctoral fellowship from the Boehringer Ingelheim Fonds. We thank Bruno Gasnier (Paris, France) for the gift of anti-VIAAT antibody and Ina Bartnik and Dagmar Magalei for expert technical assistance.

Correspondence should be addressed to Heinrich Betz, Max-Planck-Institute for Brain Research, Department of Neurochemistry, Deutschordenstrasse 46, D-60528 Frankfurt/Main, Germany. E-mail: neurochemie@mpih-frankfurt.mpg.de.

S. Kins's present address: Center for Molecular Biology, University of Heidelberg, Im Neuenheimer Feld 282, D-69120 Heidelberg, Germany.

J. Kirsch's present address: Department of Anatomy and Cellular Neurobiology, University of Ulm, Albert-Einstein-Allee 11, D-89069 Ulm, Germany.

Copyright (C) 2002 Society for Neuroscience $\quad 0270-6474 / 02 / 225393-10 \$ 15.00 / 0$
}

protein gephyrin (Triller et al., 1985, 1987; Prior et al., 1992; Bohlhalter et al., 1994). Gephyrin binds directly to the cytoplasmic loop of the glycine receptor (GlyR) $\beta$-subunit (Meyer et al., 1995), whereas a biochemical interaction between gephyrin and $\mathrm{GABA}_{\mathrm{A}}$ receptor $\left(\mathrm{GABA}_{\mathrm{A}} \mathrm{R}\right)$ subunits has never been demonstrated, suggesting an indirect mechanism of association. Gephyrin binds to tubulin with high affinity (Kirsch et al., 1991), and disruption of both the actin and microtubule cytoskeleton in neurons affect gephyrin clustering in spinal (Kirsch and Betz, 1995) but not hippocampal (Allison et al., 2000) neurons. Gephyrin is essential for the synaptic localization of GlyRs and major classes of $\mathrm{GABA}_{\mathrm{A}} \mathrm{Rs}$, as deduced from gene knock-out in mice (Feng et al., 1998; Kneussel et al., 1999) and treatment of neuronal cultures with gephyrin antisense oligonucleotides (Kirsch et al., 1993; Essrich et al., 1998). The presently available data are consistent with gephyrin forming a submembranous scaffold that immobilizes inhibitory neurotransmitter receptors at postsynaptic sites (Kneussel and Betz, 2000; Meier et al., 2001).

In contrast to the wealth of data on anchoring mechanisms, little is known about the postsynaptic targeting of neurotransmitter receptors or scaffolding proteins. A first connection between a motor protein and postsynaptic cargo molecules was identified in the case of the $\mathrm{mLin} 2 / \mathrm{mLin} 7 / \mathrm{mLin} 10 / \mathrm{NMDA}$ receptor complex and the kinesin isoform KIF17 (Setou et al., 2000). This association is likely to be relevant for the biogenesis and/or maintenance of excitatory synapses. Here we report that a yeast twohybrid screen identified the dynein light chains 1 (Dlc-1) and Dlc-2 as interaction partners of the synaptic scaffolding protein gephyrin. Gephyrin binds to Dlc-1/2 as shown by coimmunoprecipitation and glutathione $S$-transferase (GST) pulldown assays and colocalizes with Dlc-1/2 in transfected HEK293 cells. Immuno- 
stainings at the light and electron microscopic level indicate a partial colocalization of both interaction partners at inhibitory synapses. Because Dlc-1 and Dlc-2 are best characterized as light chains of cytoplasmic dynein and myosin-Va, our results suggest a role for motor proteins in the subcellular localization of gephyrin.

\section{MATERIALS AND METHODS}

Unless stated otherwise, chemicals were of analytical grade and purchased from Sigma (Taufkirchen, Germany).

Yeast two-hybrid screening. A cDNA fragment encompassing the open reading frame of the gephyrin splice variant $\mathrm{p} 1$ (Prior et al., 1992) was subcloned into pGilda (Origene, Rockville, MD) to express gephyrin amino acids $2-733$ as a lex-A fusion protein in yeast. This bait was cotransfected with an adult rat brain cDNA library cloned into pJG4-5 and the lacZ reporter plasmid pSH18-34 into the yeast strain EGY48 (all from Origene). Interaction of bait and prey fusion proteins was assayed by activation of the LEU2 and lacZ markers. Prey plasmids of positive clones were retransformed in yeast together with pGilda-gephyrin and pSH18-34 to confirm interactions. Plasmid DNA of positive clones was recovered, and their inserts were analyzed by dideoxy sequencing. The rat Dlc-2 cDNA sequence has been submitted to GenBank (accession number AY034383). For mapping of interaction domains, partial gephyrin cDNA sequences were amplified by PCR and subcloned into pGilda. All constructs were verified by dideoxy sequencing.

Coimmunoprecipitation. A cDNA fragment encompassing the open reading frame of Dlc-1 was amplified by PCR and subcloned into a pcDNA3 vector (Invitrogen, Karlsruhe, Germany) that contained sequence encoding the myc epitope tag at the $5^{\prime}$ end of the polylinker (kind gift from E. E. Evers, Max-Planck-Institute for Brain Research, Frankfurt, Germany) to allow expression as an N-terminally myc-tagged protein. A previously described pcDNA3-gephyrin construct was used to express untagged gephyrin protein (Grosskreutz et al., 2001). Lysates containing $0.5 \%(\mathrm{v} / \mathrm{v})$ Triton X-100 were prepared from individual $10 \mathrm{~cm}$ dishes of HEK293 cells expressing myc-Dlc-1 and/or gephyrin and precleared with protein G-Sepharose (Amersham Biosciences, Freiburg, Germany). After incubation with antibodies against the myc epitope (Santa Cruz Biotechnology, Heidelberg, Germany) or gephyrin [monoclonal antibody 5 (mAb5) and mAb7] (Pfeiffer et al., 1984), antigenantibody complexes were immobilized on protein G-Sepharose and washed extensively. Bound proteins were eluted by boiling in SDS sample buffer, separated by SDS-PAGE, and blotted onto nitrocellulose membranes. For immunodetection, blots were incubated with mouse antigephyrin antibody (1:1000; Transduction Laboratories, San Diego, CA) or rat anti-Dlc-1/2 antibody (1:500; Alexis, Grünberg, Germany), followed by HRP-conjugated secondary antibodies (1:4000; Dianova, Hamburg, Germany). Bound HRP was detected using chemiluminescence (SuperSignal; Pierce, Rockford, IL).

GST pulldown assays. The cDNA sequence of Dlc-1 (including $84 \mathrm{bp}$ of 5'-UTR) was recovered from pJG4-5 by restriction digest with EcoRI/ XhoI and subcloned into pGEX5X-1 (Amersham Biosciences). To generate a control construct, the same $5^{\prime}$-UTR fragment and sequence encoding amino acids $1-15$ of Dlc- 1 followed by a stop codon were amplified by PCR and cloned into the EcoRI/XhoI sites of pGEX5X-1. pGEX5X-1-gephyrin was obtained by subcloning an EcoRI/XhoI fragment from the gephyrin cDNA p1 (Prior et al., 1992) into the corresponding sites of pGEX5X-1, and GST was expressed from empty pGEX5X-1 vector. After bacterial expression of GST fusion proteins, cells were lysed in a French Press, and the lysate was cleared by centrifugation at $30,000 \times g$. Glutathione-Sepharose beads (Amersham Biosciences) were incubated with GST fusion protein for $2 \mathrm{hr}$ at $4^{\circ} \mathrm{C}$, washed, and incubated for another $2 \mathrm{hr}$ with the S2 fraction of rat brain lysate containing $0.5 \%(\mathrm{v} / \mathrm{v})$ Triton X-100. After washing, bound proteins were eluted by boiling for $5 \mathrm{~min}$ in SDS sample buffer and analyzed by Western blotting as described above. Loading of equal amounts of GST fusion proteins was verified by Ponceau staining of the Western blots.

Heterologous expression in HEK293 cells. pEGFP-N3-gephyrin encodes a gephyrin-enhanced green fluorescent protein (EGFP) fusion protein and was generated by replacing the stop codon in the gephyrin cDNA p1 (Prior et al., 1992) by a BglII site using site-directed mutagenesis and subcloning a SmaI/BglII fragment into the Eco47III/BglII sites of pEGFP-N3 (Clontech, Palo Alto, CA). pEGFP-C2-gephyrin encodes an EGFP-gephyrin fusion protein and was generated by subcloning an EcoRI/XhoI fragment of the gephyrin cDNA p1 (Prior et al., 1992) into the EcoRI/SalI-sites of pEGFP-C2 (Clontech). HEK293 cells were cultured on glass coverslips and transfected by calcium phosphate coprecipitation as described previously (Kirsch et al., 1995).

Primary cultures of rat hippocampal neurons. Hippocampi were dissected from embryonic day 18 (E18) rat embryos (Wistar) and incubated with $0.5 \mathrm{mg} / \mathrm{ml}$ papain and $10 \mu \mathrm{g} / \mathrm{ml}$ DNase I in PBS containing $10 \mathrm{~mm}$ glucose for $15 \mathrm{~min}$ at $37^{\circ} \mathrm{C}$. After washing once in DMEM supplemented with $10 \%(\mathrm{v} / \mathrm{v})$ fetal calf serum (Invitrogen), $25 \mu \mathrm{g} / \mathrm{ml}$ pyruvate, and 2 $\mathrm{mm}$ glutamine, cells were dissociated by trituration and seeded in DMEM containing supplements at a density of 30,000-60,000 cells per well onto $14 \mathrm{~mm}$ glass coverslips coated with poly-L-ornithine $(1.5 \mu \mathrm{g} /$ $\mathrm{ml}$ ). After $3 \mathrm{hr}$, the medium was replaced with Neurobasal medium containing $2 \mathrm{~mm}$ glutamine, $25 \mu \mathrm{g} / \mathrm{ml}$ pyruvate, and $2 \%(\mathrm{v} / \mathrm{v})$ B27 supplement (Invitrogen). All media contained $50 \mathrm{IU} / \mathrm{ml}$ penicillin and 50 $\mu \mathrm{g} / \mathrm{ml}$ streptomycin (Invitrogen). At $3 \mathrm{~d}$ in vitro (DIV), $3 \mu \mathrm{M} 1-\beta$-Darabinof uranosylcytosine was added to suppress astrocyte growth. Every week, one-third of the culture medium was exchanged for fresh medium. For experiments with gephyrin $(-/-)$ neurons, heterozygous gephyrin mutant mice were mated, and primary hippocampal cultures from individual E18 embryos were prepared as described above. Genotyping was performed by PCR on genomic DNA isolated from the tail of individual embryos.

Transfection of hippocampal neurons. Neurons cultured at a density of 60,000 cells/14 mm coverslip were transfected at day 12 or 13 in vitro by a calcium phosphate precipitation protocol. Per well, $2 \mu \mathrm{g}$ of DNA in 12.5 $\mu \mathrm{l}$ of $250 \mathrm{mM} \mathrm{CaCl}_{2}$, mixed with the same amount of $2 \times N, N$-bis-(2hydroxyethyl)-2-aminoethane sulfonic acid-buffered saline, $\mathrm{pH} 6.95$, were added to the culture medium. For each transfection, $0.5 \mu \mathrm{g}$ of gephyrin expression vector and $1.5 \mu \mathrm{g}$ of pcDNA3 vector (Invitrogen) were used. The precipitate was carefully removed after $1 \mathrm{hr}$ and replaced by $350 \mu \mathrm{l}$ of conditioned medium and $150 \mu \mathrm{l}$ of fresh Neurobasal medium.

Immunofluorescence staining. Cells were fixed with $4 \%(\mathrm{w} / \mathrm{v})$ paraformaldehyde (PFA)-PBS for 12 min, permeabilized with $0.2 \%$ (v/v) Triton $\mathrm{X}-100$ for $4 \mathrm{~min}$, and then blocked with $1 \%(\mathrm{w} / \mathrm{v})$ bovine serum albumin (Applichem, Darmstadt, Germany) in PBS for 30 min. Antibody staining was performed by incubation for $2 \mathrm{hr}$ with primary antibodies and $45 \mathrm{~min}$ for secondary antibodies in blocking buffer. GFP was visualized by autofluorescence. The following antibodies were used: monoclonal antibody mAb7 against gephyrin (Pfeiffer et al., 1984), monoclonal antisynaptophysin (SVP38) from Sigma, monoclonal anti-myc tag (9E10) from Roche (Mannheim, Germany), rabbit anti-Dlc antibody Dlc-2/12 (Naisbitt et al., 2000) and rabbit anti-vesicular inhibitory amino acid transporter (VIAAT) (Dumoulin et al., 1999). Secondary antibodies were Alexa goat anti-rabbit-488 and anti-mouse-594 from Molecular Probes (Eugene, OR). Antibody dilutions were 1:200 (mouse antisynaptophysin), 1:400 (anti-myc tag and mAb7 anti-gephyrin), and 1:10 (anti-Dlc). Secondary antibodies were diluted 1:1000. Immunostainings were analyzed using a Leica (Bensheim, Germany) TCS-SP confocal laser scanning microscope. All pictures are single confocal sections averaged four to eight times to reduce noise. Colocalization indices were determined using the MetaMorph Imaging Software, version 4.6 (Universal Imaging, West Chester, PA). In brief, images of single fluorescence channels were thresholded and binarized. Objects in the green channel exceeding a minimal size were counted. An object was considered to colocalize if $>25 \%$ of its area were covered by signal in the second channel.

Immunoelectron microscopy. Adult Sprague Dawley rats were anesthetized with pentobarbital $(60 \mathrm{mg} / \mathrm{kg}$ body weight) and intracardially perfused with $4 \%(\mathrm{w} / \mathrm{v})$ PFA and $0.1 \%(\mathrm{w} / \mathrm{v})$ glutaraldehyde in PBS. After dissection, the cervical spinal cord was kept overnight in 4\% PFA at $4^{\circ} \mathrm{C}$. Vibratome sections $(100 \mu \mathrm{m})$ were cryoprotected [ $3 \mathrm{hr}$ in $20 \%$ (v/v) glycerol and $20 \%(\mathrm{w} / \mathrm{v})$ saccharose in PBS], permeabilized by freeze thawing, extensively rinsed in PBS, and immersed for $20 \mathrm{~min}$ in $50 \mathrm{~mm}$ ammonium chloride and for $30 \mathrm{~min}$ in PBS containing $0.1 \%$ (w/v) gelatin (PBSg). For the detection of Dlc, vibratome sections were incubated for $12 \mathrm{hr}$ at $4^{\circ} \mathrm{C}$ in PBSg with rabbit anti-Dlc antibody (1:10), and antibody binding sites were detected using a goat biotinylated (1:100 in PBSg; Vector Laboratories, Burlingame, CA) or nanogold-coupled anti-rabbit antibody (1:100 in PBSg; Nanoprobe, Stony Brook, NY). For detection of gephyrin, a monoclonal antibody was used (1:100; Alexis, San Diego, CA). The biotinylated antibodies were revealed using an ABC immunoperoxidase method (Elite Vectastain; Vector Laboratories) (for details, see Colin et al., 1998). Gold particles were intensified for $7 \mathrm{~min}$ at $20^{\circ} \mathrm{C}$ with HQ silver kit (Nanoprobe) and subsequently gold toned as described previously (Gardiol et al., 1999). After dehydration and osmification, the 


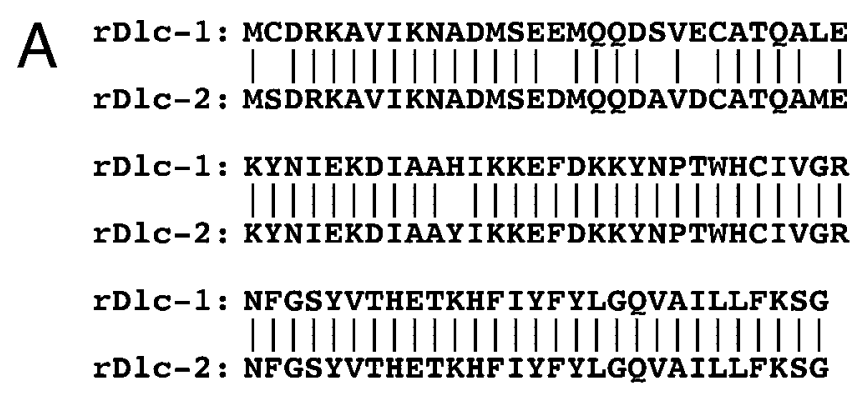

B

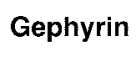

2

$2 \quad 152$

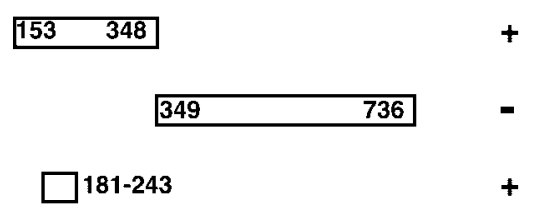

Figure 1. Interaction between gephyrin and Dlc-1/2 in the yeast twohybrid system. $A$, Amino acid sequence of rat Dlc-1 and Dlc-2. Identity is indicated by a vertical bar. $B$, Schematic diagram showing the results from yeast two-hybrid analysis of the interaction between gephyrin and Dlc-1/ Dlc-2. Interaction was assayed by lacZ/LEU2 reporter gene induction on agar plates and scored as + (blue color visible after $24 \mathrm{hr}$; this is comparable with gephyrin interacting with the cytoplasmic loop of the GlyR $\beta$ subunit or with itself; data not shown) and - (no blue color after $4 \mathrm{~d}$ ). Gephyrin deletion constructs are depicted schematically, and numbers refer to amino acid positions in the gephyrin splice variant p1 (Prior et al., 1992). Identical results were obtained for Dlc-1 and Dlc-2.

sections were flat embedded. Ultrathin sections (pale yellow) were contrasted with uranyl acetate and Reynolds lead citrate for inspection with a Philips CM12 electron microscope.

\section{RESULTS}

\section{Identification of Dlc-1 and Dlc-2 as interaction partners of gephyrin}

To identify novel gephyrin-binding proteins, we performed a yeast two-hybrid screen using the full-length gephyrin clone $\mathrm{p} 1$ as bait. From $\sim 2.3 \times 10^{6}$ clones of an adult rat brain library, 150 LEU2- and lacZ-positive clones were isolated. Among these, 32 independent clones coded for rat Dlc-1/PIN [for protein inhibitor of neuronal nitric oxide synthase (nNOS)] (Jaffrey and Snyder, 1996; King et al., 1996) and 18 for the rat homolog of human Dlc-2 (Naisbitt et al., 2000). Most of these clones contained the complete open reading frame of Dlc-1 or Dlc-2, with only 4 of 14 clones sequenced encoding Dlc-1 proteins lacking the first two or six amino acids. Dlc-1 and Dlc-2 did not activate reporter gene transcription in yeast alone, nor did they interact with a variety of control bait proteins (data not shown and Fig. $1 B$ ). Rat Dlc-1 and Dlc-2 share $93 \%$ identity at the amino acid level (Fig. $1 \mathrm{~A}$ ) and are $100 \%$ identical to their respective human homologs. Both rat Dlc proteins are 89 amino acids long and belong to a family of highly conserved light chains of cytoplasmic and flagellar dyneins, with homologs identified in human, Drosophila melanogaster, Caenorhabditis elegans, and Chlamydomonas reinhardtii (King et al., 1996). In addition, a protein homologous to Dlc-2 was reported to be a stoichiometric component of the myosin-Va complex in chick brain (Espindola et al., 2000). Rat Dlc-1 has also been described as PIN, because it interacts with nNOS and is able to inhibit nNOS during heterologous expression in HEK293 cells (Jaffrey and Snyder, 1996).

To identify the exact region of gephyrin that interacts with Dlc- $1 / 2$, we generated deletion constructs and tested their binding to Dlc- $1 / 2$ in the yeast two-hybrid system. A fragment encompassing amino acids 153-348 of gephyrin, which link the $\mathrm{N}$ - and C-terminal domains bearing homology to enzymes involved in molybdenum cofactor biosynthesis (Prior et al., 1992; Feng et al., 1998), was sufficient to interact with Dlc-1/2 (Fig. 1B). The binding domain could be further refined to a fragment of 63 amino acids corresponding to residues 181-243 of gephyrin. None of three subfragments of Dlc- $1 / 2$ examined was able to bind to gephyrin (data not shown), suggesting that proper folding of the polypeptide requires the entire amino acid sequence. Our results identify rat Dlc-1/2 as two highly homologous gephyrininteracting proteins and define amino acids $181-243$ of gephyrin as its Dlc-binding motif.

\section{Gephyrin binds to Dlc-1/2 in vitro}

Coimmunoprecipitation and GST pulldown assays were used to substantiate the interaction of gephyrin and Dlc- $1 / 2$ biochemically. Myc-tagged Dlc-1 and gephyrin were expressed in HEK293 cells and immunoprecipitated using antibodies specific for the myc epitope or gephyrin. Both recombinant proteins were expressed efficiently, in addition, lower amounts of endogenous gephyrin and Dlc-1/2 could be detected (Fig. $2 A$ ). Both endogenous and recombinant gephyrin were specifically coprecipitated by anti-myc antibodies, because no enrichment was observed when myc-Dlc-1 was omitted from the transfection. When antigephyrin antibodies were used for precipitation, myc-Dlc-1 was similarly enriched in the immunoprecipitate (Fig. 2A). This interaction was specific because only low amounts (data not shown) of myc-Dlc-1 could be precipitated when gephyrin was not overexpressed.

In additional experiments, GST pulldown assays were performed with both GST-Dlc-1 and GST-gephyrin to isolate interacting proteins from a rat brain lysate. A fusion protein of GST and Dlc-1 (GST-Dlc-1) and a control protein encoding a truncated GST-Dlc-1 protein (amino acids $1-15$ of Dlc-1 only) or GST-gephyrin and GST, respectively, were expressed in Escherichia coli. Glutathione-Sepharose beads loaded with these GST fusion proteins were incubated with rat brain lysate. Gephyrin was specifically retained on beads charged with GST-Dlc-1 but did not bind to beads containing the truncated control protein (Fig. $2 B$ ). In complementary assays, Dlc-1/2 was specifically enriched upon binding to GST-gephyrin, whereas no interaction with GST alone was observed (Fig. $2 C$ ). Thus, the interaction of gephyrin with Dlc-1/2 could be verified by two independent biochemical assays.

The GST pulldown assay was also used to confirm the relevance of the Dlc-binding motif characterized in the yeast twohybrid system. The cDNA sequence corresponding to amino acids 181-243 of gephyrin, which were sufficient for Dlc binding in the yeast-two hybrid system (Fig. $1 B$ ), was deleted, yielding gephyrin( $\Delta 181-243)$-GFP. This deletion mutant and gephyrinGFP were expressed in HEK293 cells and examined for Dlc binding using a pulldown assay with GST-Dlc-1. As shown in Figure 2D, GST-Dlc-1 specifically bound to gephyrin-GFP but not to gephyrin( $\Delta 181-243)$-GFP. Pulldown of endogenous gephy- 


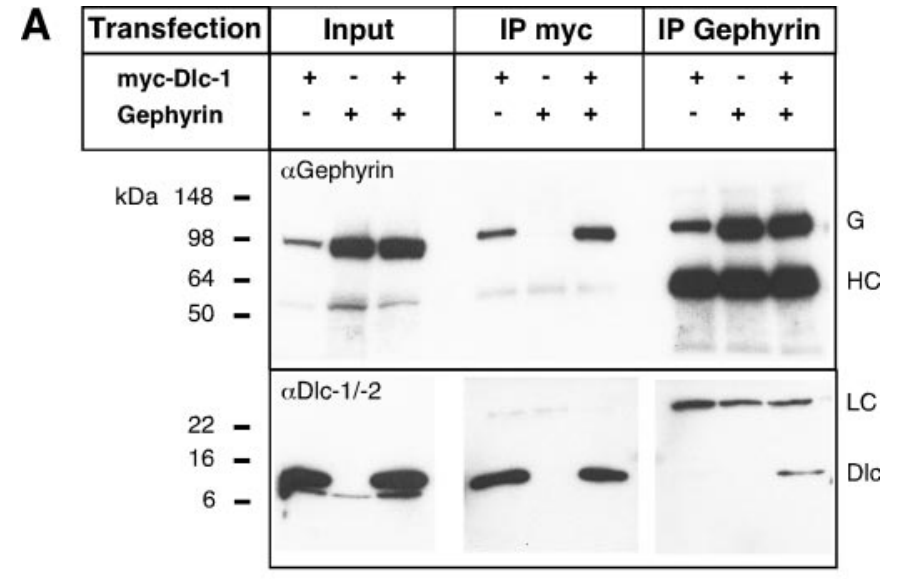

B

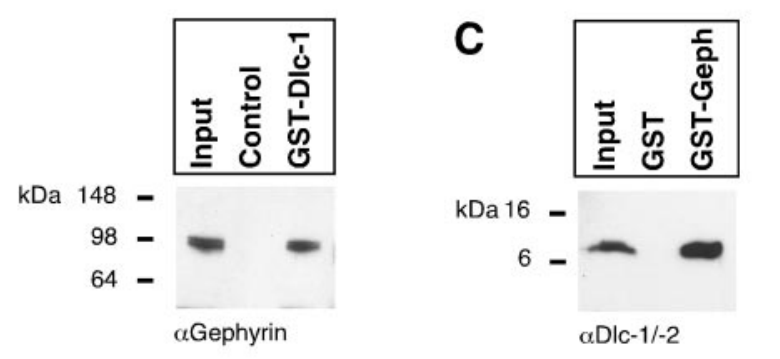

D

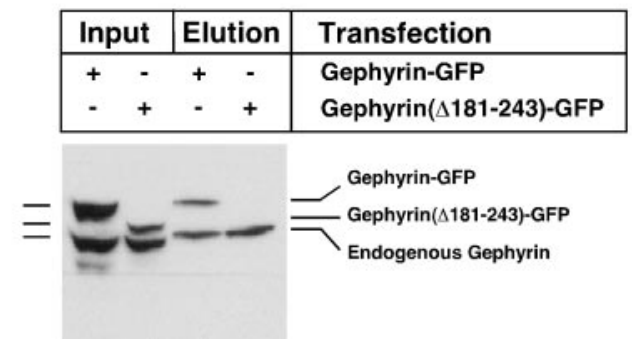

Figure 2. Binding between gephyrin and Dlc-1/2 in vitro. $A$, Dlc- 1 tagged with a myc epitope coimmunoprecipitates with gephyrin from transfected HEK293 cells. Myc-Dlc-1 and gephyrin were expressed alone or in combination, and the presence of the recombinant proteins, as well as lower amounts of endogenous proteins, were confirmed in the input lanes. Complexes between myc-Dlc-1 and gephyrin were precipitated by either myc- or gephyrin-specific antibodies immobilized on protein G-Sepharose. Both endogenous and recombinant gephyrin were specifically coimmunoprecipitated with myc-Dlc-1, and antibodies against gephyrin precipitated mycDlc-1 when gephyrin was overexpressed. $I P$, Immunoprecipitate; $G$, gephyrin; $H C$, antibody heavy chains; $L C$, antibody light chains; $D l c$, Dlc-1/2. $B$, GST-Dlc-1 pulls down gephyrin from rat brain. Glutathione Sepharose beads were loaded with either GST-Dlc-1 or a truncated control protein. Beads containing GST-Dlc-1, but not the control protein, retained gephyrin from the brain lysate, as demonstrated by immunoblotting with a gephyrinspecific antibody. $C$, GST-gephyrin specifically enriches Dlc-1/2 from rat brain. The experiment was performed as in $B$ using GST-gephyrin and GST as the negative control. Detection with an antibody recognizing Dlc-1 and Dlc-2 revealed specific binding to GST-gephyrin. D, Amino acids $181-243$ of gephyrin are required for interaction with Dlc-1. Wild-type and mutant gephyrin-GFP were expressed in HEK293 cells and tested for binding to GST-Dlc-1. Gephyrin-GFP (top band) and endogenous gephyrin (bottom band) were specifically retained by GST-Dlc-1, whereas gephyrin( $\Delta 181-243$ )-GFP (middle band) did not bind. No significant binding was detected when a truncated control protein was used instead of GST-Dlc-1 (data not shown).

rin (lower band) from both lysates served as a positive control. No significant binding to recombinant or endogenous gephyrin was detected with the truncated GST-Dlc-1 control protein (data not shown). Thus, deletion of amino acids 181-243 of gephyrin abol- ishes binding to Dlc-1. Together with the data from the yeast two-hybrid system, these results define a binding motif necessary and sufficient for interaction with Dlc.

\section{Colocalization of gephyrin and Dlc-1/2 in HEK293 cells}

To investigate whether gephyrin and Dlc-1/2 interact in mammalian cells, we expressed both proteins in HEK293 cells and examined their subcellular localization. Under these conditions, gephyrin spontaneously forms cytoplasmic aggregates (Meyer et al., 1995) (Fig. 3A, arrow). In single transfections, myc-Dlc-1 showed a diffuse cytoplasmic distribution (Fig. 3B). However, when cDNAs encoding gephyrin-GFP and myc-Dlc-1 were cotransfected, myc-Dlc-1 was efficiently recruited into the aggregates formed by gephyrin (Fig. 3D). The same result was obtained when untagged gephyrin was coexpressed with EGFP-Dlc-1 or EGFP-Dlc-2 fusion proteins (data not shown). This resembles the behavior of other established interaction partners of gephyrin, which are recruited into gephyrin aggregates during coexpression in HEK293 cells, e.g., the $\beta$-subunit of the glycine receptor or the guanine nucleotide exchange factor collybistin (Meyer et al., 1995; Kins et al., 2000).

Human Dlc-1 and, to a lesser extent, Dlc-2 are expressed in a variety of tissues, including kidney (Naisbitt et al., 2000). We therefore stained HEK293 cells for endogenous Dlc-1/2 protein and investigated whether the presence of gephyrin aggregates would alter its subcellular distribution. We used a polyclonal antiserum generated against a Dlc-2 fusion protein that recognizes both Dlc-1 and Dlc-2 with similar affinities (Naisbitt et al., 2000). Endogenous Dlc immunoreactivity (IR) showed a diffuse cytoplasmic distribution (Fig. 3C). In addition, nuclear staining of variable intensity was observed, consistent with results by Herzig et al. (2000). During heterologous expression of gephyrin-GFP, however, some Dlc immunoreactivity was recruited to the gephyrin aggregates (Fig. 3E). Thus, both recombinant and endogenous Dlc interact with gephyrin in transfected mammalian cells.

We also expressed gephyrin( $\Delta 181-243)$-GFP in HEK293 cells. This deletion mutant formed cytosolic aggregates in a manner indistinguishable from those generated by wild-type gephyrin (Fig. $3 F$ ); however, it did not recruit myc-Dlc-1 immunoreactivity during cotransfection (Fig. $3 F$, arrows). Similarly, no interaction was observed when endogenous Dlc protein was analyzed by immunostaining (data not shown). These data confirm the importance of amino acids 181-243 for Dlc-1/2 binding in intact cells.

\section{Dlc-1/2 show both cytoplasmic and synaptic localization in cultured neurons}

To examine whether Dlc- $1 / 2$ colocalize with gephyrin at inhibitory synapses, we stained primary hippocampal neurons differentiated for $20 \mathrm{~d}$ in vitro with antibodies against Dlc. In addition to a granular cytoplasmic distribution, similar to that observed in HEK293 cells, punctate Dlc immunoreactivity was found along the plasma membrane of dendrites and cell bodies (Fig. 4A,B). By double labeling, this pattern was compared with the localization of gephyrin and a general presynaptic marker protein, synaptophysin. The Dlc-immunoreactive punctae colocalized well with the synaptophysin signal, indicating synaptic localization (Fig. 4A). A major fraction, but not all, of the Dlc-positive sites also stained positive for gephyrin (Fig. $4 B$, arrow indicates lack of 

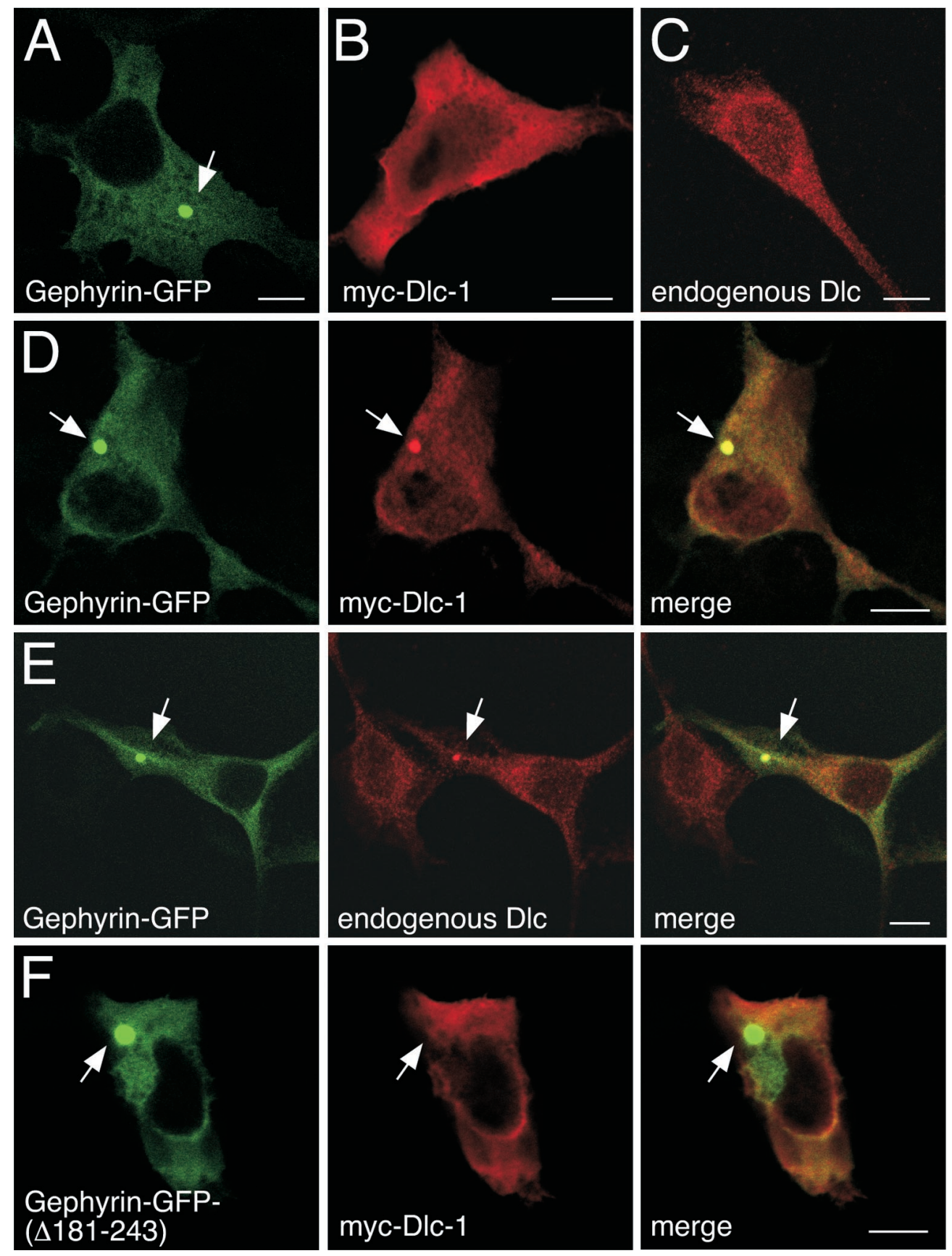

Figure 3. Recombinant and endogenous Dlc- $1 / 2$ colocalize with gephyrin in transfected HEK293 cells. A, Gephyrin-GFP overexpression leads to the formation of characteristic aggregates in HEK293 cells (arrow), whereas myc-Dlc-1 transfected alone displays a diffuse cytoplasmic distribution $(B)$. Endogenous Dlc protein is localized in the cytoplasm with no obvious compartmentalization $(C)$. Both endogenous and recombinant Dlc proteins also show nuclear localization to a variable degree. $D$, Double transfection of gephyrin-GFP (green) and myc-Dlc-1 (red) leads to recruitment of Dlc-1 to gephyrin aggregates (arrows), indicating an interaction between both proteins. Overlap of both signals is indicated yellow in the merged picture. $E$, In cells transfected with cDNA for gephyrin-GFP alone, endogenous Dlc protein (red) colocalizes with aggregates of gephyrin (green, arrows). Merge is shown in yellow. Note the homogenous distribution of Dlc in the untransfected cell to the left. F, Gephyrin-GFP( $\Delta 181-243)$ aggregates do not recruit myc-Dlc-1 in transfected cells. HEK293 cells were cotransfected with cDNAs encoding GFP-gephyrin $(\Delta 181-$ 243) and myc-Dlc-1 and stained for the myc epitope tag. GFP autofluorescence (green) shows the presence of gephyrin aggregates similar to the wild-type situation, whereas Dlc-1 (red) is not enriched in these structures. Scale bars, $10 \mu \mathrm{m}$. colocalization). A similar result was obtained in spinal cord neurons cultured for $16 \mathrm{~d}$ in vitro (data not shown). The incomplete colocalization of Dlc-immunoreactive punctae with gephyrin, but good correlation with synaptophysin-positive terminals, indicates that Dlc is enriched at inhibitory and excitatory synapses.

While investigating the subcellular localization of Dlc proteins in cultured hippocampal neurons, we noticed a variability between individual cells in the extent of synaptic Dlc immunoreactivity that seemed to depend on the density of neighboring cells and neurites. Therefore, we plated hippocampal cultures at different densities and performed immunostaining for Dlc after $20 \mathrm{~d}$ in vitro. In high-density cultures (60,000 cells per coverslip) (Fig. $4 E$ ), Dlc immunoreactivity was intensely cytoplasmic, with almost no detectable enrichment at synaptic sites. At lower cell densities (30,000 and 40,000 cells per coverslip) (Fig. 4C,D), the synaptic localization of Dlc became apparent and cytosolic staining decreased to low levels (Fig. 4C). The same observation was made in cultures maintained for 11 DIV (data not shown), excluding effects on cell survival. The presence of Dlc immunoreactivity at inhibitory postsynaptic sites provides evidence for a physiological relevance of the interaction between Dlc-1/2 and gephyrin in neurons. Our findings also suggest that this interaction is subject to a regulatory process that might be linked to the extent of cell interactions.

\section{Postsynaptic localization of Dlc demonstrated by immunoelectron microscopy}

The enrichment of Dlc at synaptic sites was examined at the EM level in the ventral spinal cord in which neuronal activity is 
Figure 4. Gephyrin and Dlc colocalize at inhibitory synapses in cultured hippocampal neurons. Hippocampal neurons were cultured for $20 \mathrm{DIV}$ and stained for the indicated proteins. A, Colocalization of Dlc and synaptophysin at synaptic sites. The merged image shows synaptophysin immunoreactivity in red and Dlc staining in green; overlapping signals are yellow. Dlc is not exclusively synaptic but displays prominent cytosolic staining in addition. Insets, $2 \times$ magnification. $B$, Colocalization of Dlc and gephyrin at inhibitory synapses. Many, but not all, Dlcpositive punctae stain positive for gephyrin. Display as in $A$. $C-E$, Dependence of the degree of membraneassociated Dlc immunoreactivity on culture density. Hippocampal neurons were plated at densities of 30,000 (C), 40,000 $(D)$, or $60,000(E)$ per $14 \mathrm{~mm}$ coverslip and allowed to differentiate for 20 DIV. Dlc staining reveals variable ratios of cytosolic and submembranous Dlc signal intensity. Note the high number of fine neurites, likely to represent both axons and dendrites, in the high-density culture. Scale bars, $10 \mu \mathrm{m}$.
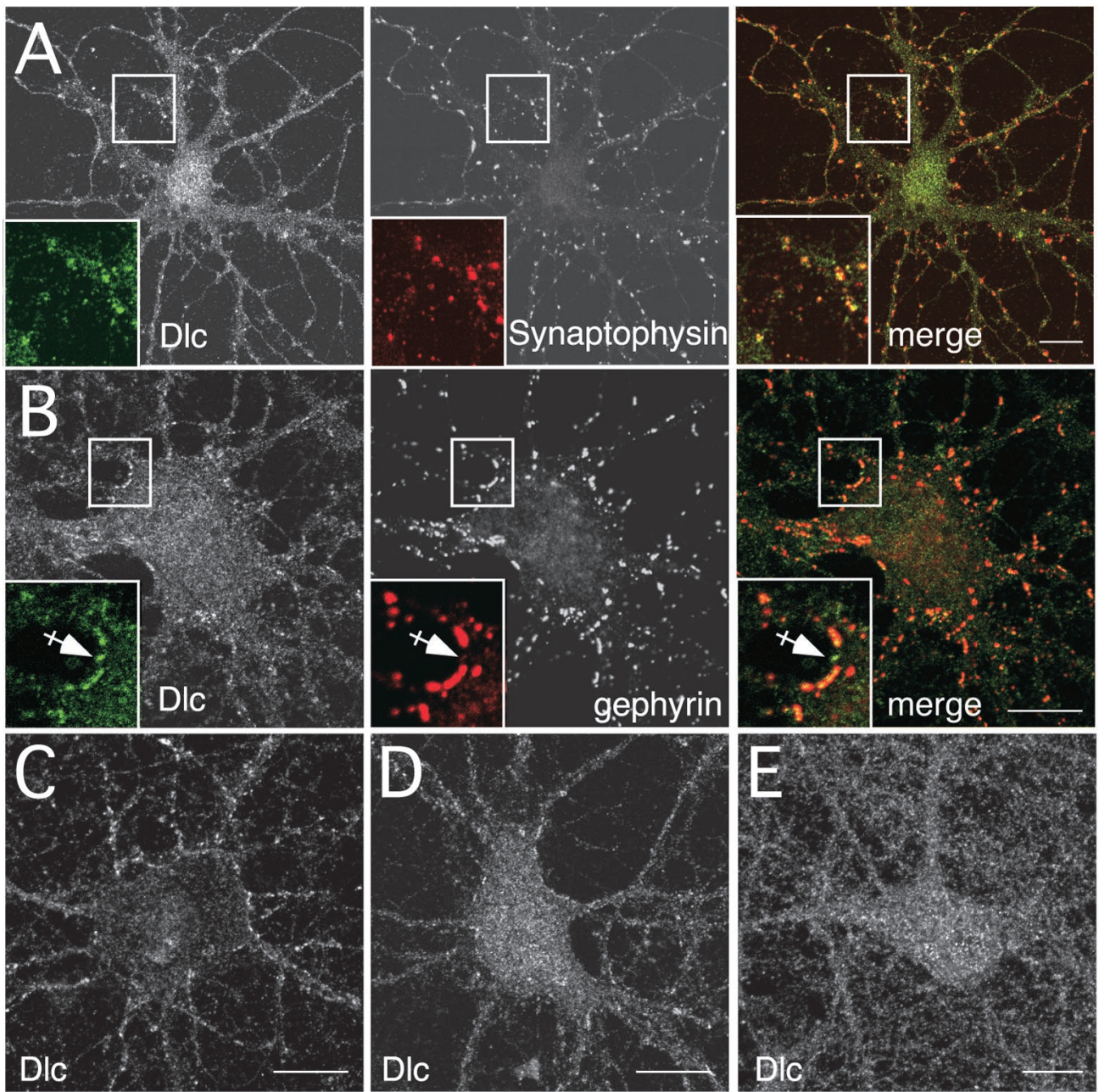

controlled by glycine- and GABA-mediated inhibition (Todd et al., 1996). Using an immunoperoxidase method, Dlc-IR was detected in intracellular compartments and was consistently found at synaptic sites. The immunodeposits often decorated the postsynaptic side of symmetrical type II contacts, in front of presynaptic terminal boutons containing a pleiomorphic population of vesicles (Fig. 5A1,A2). Even when the enzymatic reaction product masked the postsynaptic differentiations, these synaptic junctions could be classified as inhibitory by their narrow (15-20 nm) synaptic cleft (Triller and Sotelo, 1997). Furthermore, not all of these contacts were stained, as exemplified for a bouton with two synaptic contacts of which only one contained Dlc-IR (Fig. $5 A 2$ ). Electron-dense enzymatic reaction product was also found in front of some boutons that contained spherical synaptic vesicles and were associated with a wider $(25-30 \mathrm{~nm})$ synaptic cleft (Fig. $5 B)$. These contacts correspond to asymmetrical type I synapses, which are most likely excitatory (Triller and Sotelo, 1997). A weak and diff use Dlc immunoreactivity could also be detected in the neuronal cytoplasm and near vesicular structures (data not shown). Notably, intracellular Dlc-IR was found at the edge of the Golgi apparatus using either immunoperoxidase (data not shown) or preembedding immunolabeling and gold-toned silverintensified nanogold particles (Fig. 5C). This localization is compatible with a role of Dlc in motor protein complexes, because cytoplasmic dynein, kinesin, and myosin are involved in Golgi dynamics (Lippincott-Schwartz, 1998). Quantification of the im- munogold stainings revealed that most Dlc-1/2-associated gold particles were found in close apposition with the cytoskeleton $(62 \%)$. The remainder was associated with intracellular membranes $(18 \%)$, located in the cytosol $(8 \%)$ or in direct vicinity $(<20 \mathrm{~nm})$ of postsynaptic $(6 \%)$ and extrasynaptic $(6 \%)$ plasma membranes. At the synaptic level, double detection of gephyrin and Dlc with immunoperoxidase and gold-toned silver-intensified nanogold particles, respectively, confirmed that only a fraction of the gephyrin-containing postsynaptic differentiations contained Dlc-IR. Notably, Dlc-IR was detected at the edge of postsynaptic differentiations (Fig. 5D1,D2).

\section{Dlc binding is not essential for the synaptic localization of gephyrin in neurons}

Dlc-1 has been proposed to serve as an adaptor between the cytoplasmic dynein motor complex and cargo molecules (King, 2000). Therefore, we examined whether the interaction with Dlc might contribute to the subcellular localization of gephyrin in nerve cells. For this purpose, we expressed either wild-type GFP-gephyrin or the GFP-gephyrin mutant deficient in Dlc binding in cultured hippocampal neurons at 12 DIV and analyzed their distribution $20 \mathrm{hr}$ after transfection. Inhibitory synapses were identified by staining for VIAAT (Dumoulin et al., 1999), and colocalization of GFP and VIAAT signal was evaluated using automated image analysis. GFP-gephyrin displays a complex localization pattern in transfected neurons. Besides some 


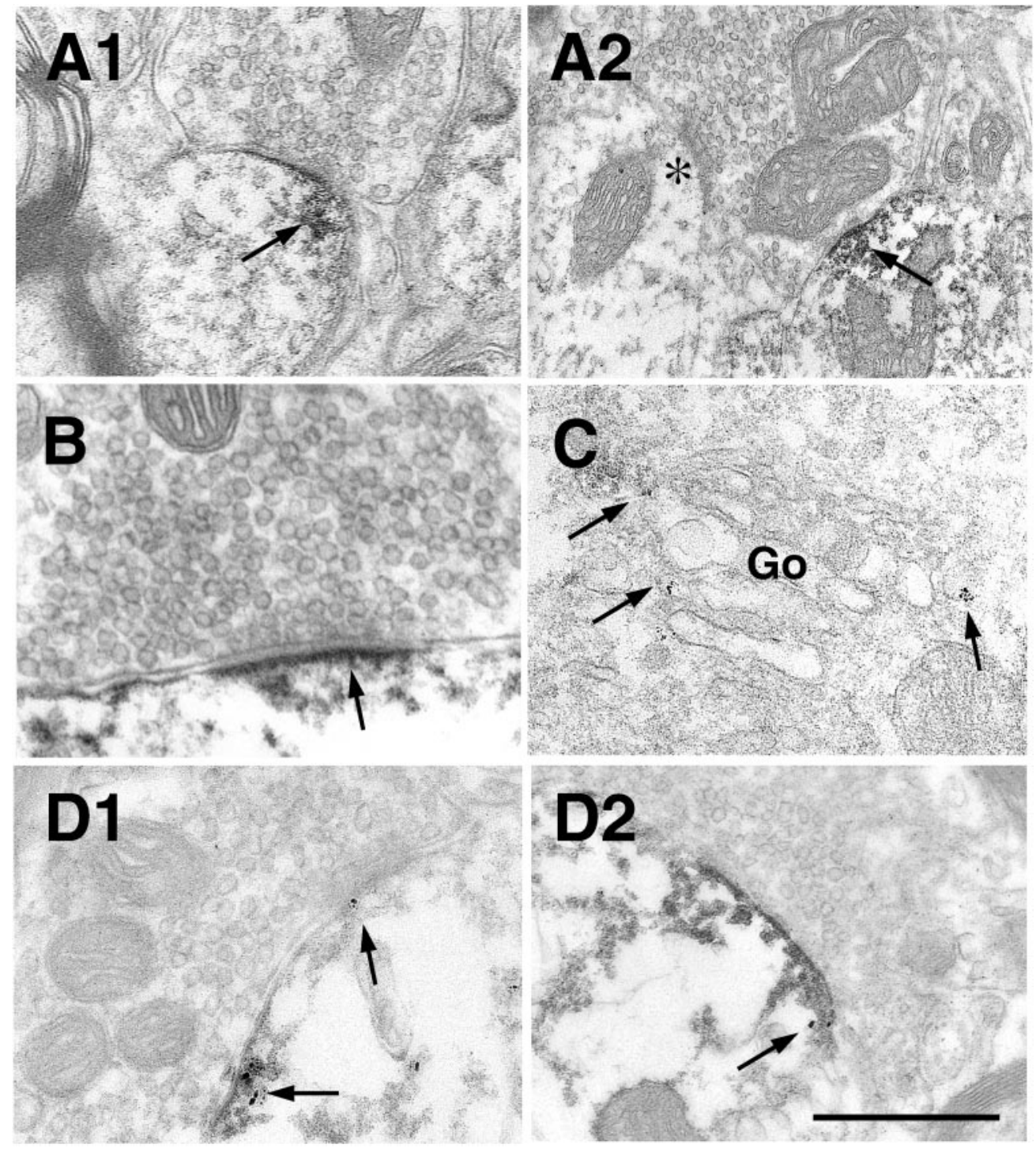

Figure 5. Ultrastructural localization of Dlc immunoreactivity in neurons. $A 1-A 2$, Detection of Dlc immunoperoxidase associated electron-dense deposits (arrows) at postsynaptic differentiations adjacent to synaptic boutons containing pleiomorphic populations of synaptic vesicles. Note that not all postsynaptic differentiations associated with a synaptic bouton contain Dlc-associated immunoreactivity (asterisk in A2). B, Detection of Dlc-associated electron-dense deposits (arrow) in front of a synaptic bouton containing spherical synaptic vesicles. $C$, Detection of Dlc-IR at the membrane of the Golgi apparatus (Go) with gold-toned silver-intensified nanogold particles (arrows). D, Two examples of simultaneous detection of gephyrinassociated electron-dense immunoperoxidase deposits and Dlc-associated gold-toned silver-intensified nanogold particles (arrows). Note that the Dlc immunoreactivity predominates at the periphery of the postsynaptic differentiations. Scale bar: $A 1,0.50 \mu \mathrm{m} ; A 2,0.85$ $\mu \mathrm{m} ; B, 0.30 \mu \mathrm{m} ; C, 0.44 \mu \mathrm{m} ; D 1,0.40$ $\mu \mathrm{m} ; D 2,0.60 \mu \mathrm{m}$. diff use cytosolic staining, GFP-gephyrin was enriched in clusters near the plasma membrane of cell bodies and dendrites (Fig. 6A). Depending on the expression level, some cytosolic aggregates of GFP-gephyrin could be observed in addition. In cells expressing moderate levels of recombinant protein, the majority of GFPgephyrin clusters were colocalized with the VIAAT immunoreactivity, thus demonstrating proper synaptic targeting. A minor fraction of GFP-gephyrin hotspots that did not colocalize with VIAAT probably represent nonsynaptic aggregates of GFPgephyrin. The picture is very similar for GFP-gephyrin $(\Delta 181-$ 243), the mutant deficient in Dlc binding (Fig. 6B). A large number of GFP-positive clusters near the plasma membrane aligned well with the VIAAT signal, whereas only minor amounts of the recombinant protein were distributed diffusely or formed aggregates in the cytoplasm.

Quantification of the colocalization between GFP-gephyrin clusters and VIAAT immunoreactivity by automated image analysis yielded values of 62.8 and $72.4 \%$, respectively, for the cells shown in Figure $6, A$ and $B$. We applied this analysis to the complete data sets of two independent experiments, regardless of GFP-gephyrin expression levels. The actual numbers thus are not absolute but can be used for comparison of the two GFP-gephyrin constructs. For GFP-gephyrin, we obtained colocalization values of $46.1 \pm 4.2 \%$ (mean $\pm \mathrm{SEM} ; n=21$ cells $)$ and $38.6 \pm 3.5 \%(n=$ $30)$, and clusters of GFP-gephyrin( $\Delta 181-243)$ colocalized to $43.5 \pm 3.4 \%(n=30)$ and $37.7 \pm 3.5 \%(n=28)$ with VIAATpositive terminals.

Gephyrin is able to oligomerize into higher-order structures (Kirsch et al., 1995; Kneussel and Betz, 2000; Sola et al., 2001). It is therefore conceivable that coassembly with endogenous gephyrin could mask a targeting defect of GFP-gephyrin( $\Delta 181-243)$. We therefore repeated the experiment described above in the gephyrin knock-out background. In hippocampal neurons derived from gephyrin-deficient mice (Feng et al., 1998), deletion of the Dlc-binding region again had no effect on the synaptic localization of GFP-gephyrin fusion proteins (data not shown). Colocalization indices were $41.9 \pm 3.2 \%(n=21)$ for GFP-gephyrin and $40.7 \pm 3.4 \%$ ( $n=31$, pooled data from two experiments) for GFP-gephyrin( $\Delta 181-243)$, respectively. These numbers are almost identical to each other and the values obtained in wild-type neurons. The presence of endogenous gephyrin thus did not mask a targeting defect of GFP-gephyrin( $\Delta 181-243)$. Therefore, under the experimental conditions tested, Dlc binding seems not to be required for the synaptic targeting of gephyrin. 
Figure 6. Gephyrin targeting to inhibitory synapses in transfected hippocampal neurons does not require the Dlc-binding domain. $A$, GFP-gephyrin accumulates at inhibitory synapses. Hippocampal neurons cultured for 12 DIV were transfected with pEGFP-C2gephyrin. After $20 \mathrm{hr}$, cells were fixed and stained for VIAAT (red) to indicate inhibitory terminals. GFP autofluorescence is shown in green, and merge between red and green channels is shown in yellow. GFP-gephyrin forms numerous hotspots near the plasma membrane of cell body and dendrites, the large majority of which colocalize with VIAAT immunoreactivity. $B$, GFP-gephyrin( $\Delta 181-243)$ does not display a localization defect when compared with wild-type GFP-gephyrin. The experiment was performed as in $A$, except that neurons were transfected with pEGFP-C2-gephyrin( $\Delta 181-243)$. Most of the submembranous clusters of GFP-gephyrin $(\Delta 181-243)$ colocalize with the VIAAT signal, indicating undisturbed synaptic targeting. Scale bar, $10 \mu \mathrm{m}$.
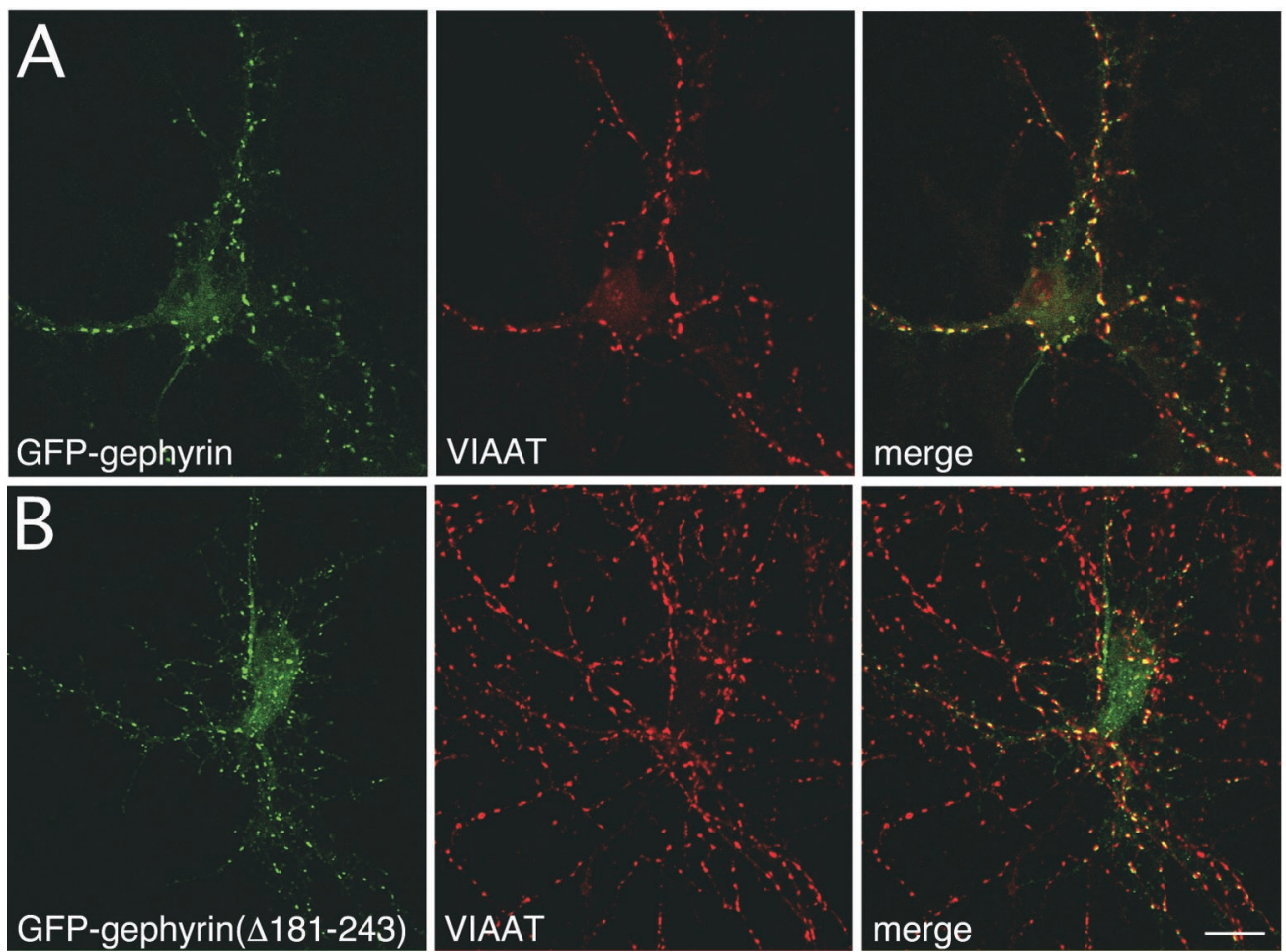

\section{DISCUSSION}

\section{Gephyrin binds to dynein light chains 1 and 2}

Here, we used yeast two-hybrid screening to identify Dlc-1/2 as novel binding partners of the postsynaptic scaffolding protein gephyrin. Deletion analysis showed that this interaction was mediated by amino acids 181-243 of gephyrin. Gephyrin bound to GST-Dlc-1 in a pulldown assay, whereas a gephyrin mutant lacking amino acids 181-243 displayed no binding. Also, gephyrin and Dlc proteins were found to interact in transfected HEK293 cells, as evident from coimmunoprecipitation and the recruitment of both recombinant and endogenous Dlc- $1 / 2$ to cytoplasmic gephyrin aggregates. In conclusion, we showed by four independent approaches that gephyrin binds to Dlc proteins and that amino acids 181-243 of gephyrin are both necessary and sufficient to mediate this interaction.

Multiple interaction partners of gephyrin are known (Kneussel and Betz, 2000), but, in most cases, the domains of gephyrin responsible for binding have not been identified. Consistent with the recently determined crystal structures of an N-terminal fragment of gephyrin (Schwarz et al., 2001; Sola et al., 2001) and of moeA, a bacterial homolog of the C-terminal domain of gephyrin (Xiang et al., 2001), gephyrin has been proposed to oligomerize via trimerization of its $\mathrm{N}$-terminal and dimerization of its C-terminal domains (Kneussel and Betz, 2000; Xiang et al., 2001). Here, for the first time, a function can be assigned to the central region linking these domains, namely binding to Dlc-1/2. Recently, a large number of Dlc-interacting proteins have been analyzed for their minimal Dlc-binding motifs using synthetic peptides (Rodriguez-Crespo et al., 2001), revealing two seemingly unrelated consensus sequences. The Dlc-binding region (amino acids 181-243) of gephyrin contains a sequence stretch of moderate homology to the Dlc-interaction sites of nNOS and GKAP (for guanylate kinase-associated protein) (five of nine and six of nine amino acids similar), which are characterized by the presence of a GIQVD core motif (GVQCE in gephyrin).

\section{Subcellular localization of Dlc proteins in neurons}

Immunostaining of cultured hippocampal neurons and immunoelectron microscopy of rat spinal cord sections revealed an enrichment of Dlc-1/2 at inhibitory synapses positive for gephyrin. Thus, an interaction between both proteins is likely to occur in neurons, in which gephyrin serves as a structural protein essential for the clustering of neurotransmitter receptors at inhibitory synapses. Dlc immunoreactivity was not enriched at all inhibitory synapses, however. In primary hippocampal neurons cultured at high density, Dlc immunoreactivity was distributed rather uniformly in the cytosol, and immunoelectron microscopy consistently identified a fraction of gephyrin-positive synapses negative for Dlc. This variability and the preferential localization of Dlc proteins at the edges of postsynaptic specializations suggest that Dlc-1/2 are unlikely to be structural components of inhibitory synapses.

Dlc-1/2 are also enriched in dendritic spines of hippocampal neurons, in which they colocalize with GKAP and PSD-95 (Naisbitt et al., 2000). Dlc proteins bind directly to GKAP, and a complex consisting of PSD-95, GKAP, Dlc-1/2, and myosin-Va can be coimmunoprecipitated from brain tissue. These findings agree with our observation of Dlc immunoreactivity at putative excitatory synapses as classified by morphological criteria. In addition to the synaptic staining, a major fraction of Dlc immunoreactivity was found to be associated with the cytoskeleton, supporting its role in motor protein-mediated transport events. Our electron microscopic analysis also revealed prominent Dlc immunoreactivity at the periphery of Golgi stacks, in which Dlc-1/2 and associated motor proteins may be involved in the anchoring or dynamics of this organelle (Lippincott-Schwartz, 1998).

\section{Dlc-1/2 are subunits of cytoplasmic dynein and myosin-Va}

Mammalian Dlc proteins were first described as light chains of cytoplasmic dynein (King et al., 1996), a large multi-protein complex mediating movement toward minus ends of microtubule 
tracks. Cytoplasmic dynein is involved in mitotic spindle function, nuclear migration, the subcellular localization of the Golgi complex and lysosomes, and the retrograde transport of vesicles in axons (Hirokawa et al., 1998). Recently, a chicken homolog of Dlc-2 was found to be a stoichiometric component of myosin-Va (Espindola et al., 2000), an unconventional myosin that is involved in actin-based vesicle transport (Wu et al., 2000) and enriched in the postsynaptic density of excitatory synapses (Walikonis et al., 2000).

Dlc proteins form dimers in which both monomers can bind to ligands (Tochio et al., 1998; Liang et al., 1999). Thus, interaction with Dlc-1/2 may either promote dimerization of an interaction partner or physically link two unrelated binding proteins. This structural feature, together with the stoichiometric association of the dynein and myosin-Va complexes with Dlc proteins (King et al., 1996; Espindola et al., 2000) and the number and functional diversity of Dlc-binding proteins, suggests that the Dlc dimer might recruit various types of cargo to motor protein complexes. Such an adaptor function has been demonstrated most convincingly for the $14 \mathrm{kDa}$ dynein light chain tctex- 1 in the transport of rhodopsin-bearing vesicles (Tai et al., 1999), but, also for Dlc-1/2, there are data supporting this hypothesis. Interactions with Dlc-1 and Dlc-2 have been found to sequester the proapoptotic Bcl-2 family members Bim and Bmf to the microtubule and actin cytoskeleton, respectively (Puthalakath et al., 1999, 2001); however, a role in trafficking has not been investigated.

Evidence for an involvement of Dlc in dynein-mediated transport comes from Drosophila, in which Dlc-1 binds to swallow, a protein implicated in the microtubule-dependent asymmetric localization of bicoid mRNA in midoogenesis (Schnorrer et al., 2000). A swallow mutant protein incapable of binding Dlc-1 is no longer localized to the anterior pole of the oocyte and fails to restrict bicoid mRNA to this site. Also, the association of the p54 protein of African swine fever virus (ASFV) with Dlc-1 in infected host cells could account for the molecular link between virus particles and the dynein motor complex (Alonso et al., 2001). In ASFV-infected cells, p54 and Dlc-1 colocalize at the microtubule organizing center, a key target of transport toward microtubule minus ends. Notably, inhibition of dynein function impedes ASFV infection (Alonso et al., 2001).

\section{A possible role for motor proteins in gephyrin trafficking}

The interaction of gephyrin with Dlc-1/2 suggests that the subcellular localization of gephyrin may depend on motor proteins. Active transport is known mainly for vesicular cargo, and an association with endomembranes has been demonstrated for other synaptic proteins that bind to motor proteins, e.g., the mLin-10/mLin-7/mLin-2 complex or PSD-95 (El-Husseini et al., 2000; Setou et al., 2000). For gephyrin, the interaction with a vesicular compartment could be mediated by association with GlyR and $\mathrm{GABA}_{\mathrm{A}} \mathrm{R}$ complexes or lipid modification. Potentially, dendritic transport of gephyrin could occur in two directions, either anterogradely, toward the synapse, or retrogradely, toward the cell body. Dendritic microtubules show a mixed orientation, with the exception of distal segments in which plus ends point toward the growth cone (Baas et al., 1988). Cytoplasmic dynein could therefore mediate both anterograde and retrograde transport in large parts of the dendrite. The role of myosin-Va in dendrites is equally unclear and may include short-distance trafficking at the cell cortex, as well as cooperation with a microtubule-based motor in the long-distance movement of cargo vesicles. The interaction between Dlc-1/2 and GKAP, a protein localized at excitatory synapses, may point to a role of Dlc proteins and myosin-Va in actin-based trafficking in dendritic spines (Naisbitt et al., 2000).

Motor protein-mediated transport is a transient process that is likely to affect only a minor fraction of cargo proteins at a given time. Thus, the moderate enrichment of Dlc immunoreactivity at synaptic sites is compatible with the interpretation that Dlc proteins link gephyrin to an active transport process. In this context, complexes of gephyrin and Dlc- $1 / 2$ could represent either active motor units or cargo protein preselected for transport. We attempted to examine whether Dlc- $1 / 2$ and associated motor proteins might be required for the subcellular trafficking of gephyrin. However, our transfection experiments using mutant GFP-gephy$\operatorname{rin}(\Delta 181-243)$ in hippocampal neurons failed to demonstrate a requirement for an interaction with Dlc- $1 / 2$ in the synaptic targeting of gephyrin. This cannot be attributed to coassembly of the mutant protein with endogenous gephyrin, because targeting was unaffected also in gephyrin $(-/-)$ neurons. We therefore suggest that transport of the Dlc-gephyrin complex might proceed into the retrograde direction.

The interaction of gephyrin with Dlc-1/2, i.e., subunits of cytoplasmic dynein and myosin-Va, supports the idea that gephyrin deposition at and/or removal from synapses may be regulated in a highly dynamic manner. A precise control of the number of gephyrin molecules is important for synaptic efficacy, because the size and density of the gephyrin scaffold will directly influence the number of postsynaptic receptors and thus the size of the synaptic response (Lim et al., 1999; Meier et al., 2001). Clearly, the hypothesis that motor proteins are involved in the intracellular trafficking of gephyrin requires additional experimental verification. However, our data provide the first report for an interaction of a component of inhibitory postsynaptic specializations with motor protein subunits and thus represent a starting point for the investigation of protein transport processes in inhibitory synapse formation and function.

\section{REFERENCES}

Allison DW, Chervin AS, Gelfand VI, Craig AM (2000) Postsynaptic scaffolds of excitatory and inhibitory synapses in hippocampal neurons: maintenance of core components independent of actin filaments and microtubules. J Neurosci 20:4545-4554.

Alonso C, Miskin J, Hernaez B, Fernandez-Zapatero P, Soto L, Canto C, Rodriguez-Crespo I, Dixon L, Escribano JM (2001) African swine fever virus protein p54 interacts with the microtubular motor complex through direct binding to light-chain dynein. J Virol 75:9819-9827.

Baas PW, Deitch JS, Black MM, Banker GA (1988) Polarity orientation of microtubules in hippocampal neurons: uniformity in the axon and nonuniformity in the dendrite. Proc Natl Acad Sci USA 85:8335-8339.

Bohlhalter S, Möhler H, Fritschy JM (1994) Inhibitory neurotransmission in rat spinal cord: co-localization of glycine- and GABAAreceptors at GABAergic synaptic contacts demonstrated by triple immunofluorescence staining. Brain Res 642:59-69.

Burack MA, Silverman MA, Banker G (2000) The role of selective transport in neuronal protein sorting. Neuron 26:465-472.

Colin I, Rostaing P, Augustin A, Triller A (1998) Localization of components of glycinergic synapses during rat spinal cord development. J Comp Neurol 398:359-372.

Craig AM, Banker G (1994) Neuronal polarity. Annu Rev Neurosci 17:267-310.

Dumoulin A, Rostaing P, Bedet C, Lévi S, Isambert MF, Henry JP, Triller A, Gasnier B (1999) Presence of the vesicular inhibitory amino acid transporter in GABAergic and glycinergic synaptic terminal boutons. J Cell Sci 112:811-823.

El-Husseini AE, Craven SE, Chetkovich DM, Firestein BL, Schnell E, Aoki C, Bredt DS (2000) Dual palmitoylation of PSD-95 mediates its vesiculotubular sorting, postsynaptic targeting, and ion channel clustering. J Cell Biol 148:159-171.

Espindola FS, Suter DM, Partata LBE, Cao T, Wolenski JS, Cheney RE, King SM, Mooseker MS (2000) The light chain composition of chicken 
brain myosin-Va: calmodulin, myosin-II essential light chains, and 8-kDa dynein light chain/PIN. Cell Motil Cytoskeleton 47:269-281.

Essrich C, Lorez M, Benson JA, Fritschy JM, Lüscher B (1998) Postsynaptic clustering of major GABAA receptor subtypes requires the $\gamma 2$ subunit and gephyrin. Nat Neurosci 7:563-571.

Feng G, Tintrup H, Kirsch J, Nichol MC, Kuhse J, Betz H, Sanes JR (1998) Dual requirement for gephyrin in glycine receptor clustering and molybdoenzyme activity. Science 282:1321-1324.

Gardiol A, Racca C, Triller A (1999) Dendritic and postsynaptic protein synthetic machinery. J Neurosci 19:168-179.

Grosskreutz Y, Hermann A, Kins S, Fuhrmann JC, Betz H, Kneussel M (2001) Identification of a gephyrin-binding motif in the GDP/GTP exchange factor collybistin. Biol Chem 382:1455-1462.

Herzig RP, Andersson U, Scarpulla RC (2000) Dynein light chain interacts with NRF-1 and EWG, structurally and functionally related transcription factors from humans and Drosophila. J Cell Sci 113:4263-4273.

Hirokawa N, Funakoshi T, Sato-Harada R, Kanai Y (1996) Selective stabilization of tau in axons and microtubule-associated protein $2 \mathrm{C}$ in cell bodies and dendrites contributes to polarized localization of cytoskeletal proteins in mature neurons. J Cell Biol 132:667-679.

Hirokawa N, Noda Y, Okada Y (1998) Kinesin and dynein superfamily proteins in organelle transport and cell division. Curr Opin Cell Biol 10:60-73.

Jaffrey SR, Snyder SH (1996) PIN: an associated protein inhibitor of neuronal nitric oxide synthase. Science 274:774-777.

King SM (2000) The dynein microtubule motor. Biochim Biophys Acta 1496:60-75.

King SM, Barbarese E, Dillman JF, Patel-King RS, Carson JH, Pfister KK (1996) Brain cytoplasmic and flagellar outer arm dyneins share a highly conserved Mr 8000 light chain. J Biol Chem 271:19358-19366.

Kins S, Betz H, Kirsch A (2000) Collybistin, a newly identified brainspecific GEF, induces submembrane clustering of gephyrin. Nat Neurosci 3:22-29.

Kirsch J, Betz H (1995) The postsynaptic localization of the glycine receptor-associated protein gephyrin is regulated by the cytoskeleton. J Neurosci 15:4148-4156.

Kirsch J, Langosch D, Prior P, Littauer UZ, Schmitt B, Betz H (1991) The 93-kDa glycine receptor associated protein binds to tubulin. J Biol Chem 266:22242-22245.

Kirsch J, Wolters I, Triller A, Betz H (1993) Gephyrin antisense oligonucleotides prevent glycine receptor clustering in spinal neurons. Nature 366:745-748.

Kirsch J, Kuhse J, Betz H (1995) Targeting of glycine receptor subunits to gephyrin-rich domains in transfected human embryonic kidney cells. Mol Cell Neurosci 6:450-461.

Kneussel M, Betz H (2000) Clustering of inhibitory neurotransmitter receptors at developing postsynaptic sites: the membrane activation model. Trends Neurosci 23:429-435.

Kneussel M, Brandstätter JH, Laube B, Stahl S, Müller U, Betz H (1999) Loss of postsynaptic GABAA receptor clustering in gephyrin-deficient mice. J Neurosci 19:9289-9297.

Liang J, Jaffrey SR, Guo W, Snyder SH, Clardy J (1999) Structure of the PIN/LC8 dimer with a bound peptide. Nat Struct Biol 6:735-740.

Lim R, Alvarez FJ, Walmsley B (1999) Quantal size is correlated with receptor cluster area at glycinergic synapses in the rat brainstem. J Physiol (Lond) 516.2:505-512.

Lippincott-Schwartz J (1998) Cytoskeletal proteins and golgi dynamics. Curr Opin Cell Biol 10:52-59.

Meier J, Vannier C, Serge A, Triller A, Choquet D (2001) Fast and reversible trapping of surface glycine receptors by gephyrin. Nat Neurosci 4:253-260.

Meyer G, Kirsch J, Betz H, Langosch D (1995) Identification of a gephyrin binding motif on the glycine receptor $\beta$ subunit. Neuron 15:563-572.
Naisbitt S, Valtschanoff J, Allison DW, Sala C, Kim E, Craig AM, Weinberg RJ, Sheng M (2000) Interaction of the postsynaptic density95/guanylate kinase domain-associated protein complex with a light chain of myosin V, dynein. J Neurosci 20:4524-4534.

Pfeiffer F, Simler R, Grenningloh G, Betz H (1984) Monoclonal antibodies and peptide mapping reveal structural similarities between the subunits of the glycine receptor of rat spinal cord. Proc Natl Acad Sci USA 81:7224-7227.

Prior P, Schmitt B, Grenningloh G, Pribilla I, Multhaup G, Beyreuther K, Maulet Y, Werner P, Langosch D, Kirsch J, Betz H (1992) Primary structure and alternative splice variants of gephyrin, a putative glycine receptor-tubulin linker protein. Neuron 8:1161-1170.

Puthalakath H, Huang DCS, O'Reilly LA, King SM, Strasser A (1999) The proapoptotic activity of the Bcl-2 family member Bim is regulated by interaction with the dynein motor complex. Mol Cell 3:287-296.

Puthalakath H, Villunger A, O'Reilly LA, Beaumont JG, Coultas L, Cheney RE, Huang DCS, Strasser A (2001) Bmf: a proapoptotic BH3only protein regulated by interaction with the myosin $\mathrm{V}$ actin motor complex, activated by anoikis. Science 293:1829-1832.

Rodriguez-Crespo I, Yelamos B, Roncal F, Albar JP, Ortiz de Montellano PR, Gavilanes F (2001) Identification of novel cellular proteins that bind to the LC8 dynein light chain using a pepscan technique. FEBS Lett 503:135-141.

Schnorrer F, Bohmann K, Nüsslein-Volhard C (2000) The molecular motor dynein is involved in targeting swallow and bicoid RNA to the anterior pole of Drosophila oocytes. Nat Cell Biol 2:185-190.

Schwarz G, Schrader N, Mendel RR, Hecht HJ, Schindelin H (2001) Crystal structure of human gephyrin and plant Cnx1 G domains: comparative analysis and functional implications. J Mol Biol 312:405-418.

Setou M, Nakagawa T, Seog DH, Hirokawa N (2000) Kinesin superfamily motor protein KIF17 and mLin-10 in NMDA receptor-containing vesicle transport. Science 288:1796-1802.

Sheng M, Pak DT (2000) Ligand-gated ion channel interactions with cytoskeletal and signaling proteins. Annu Rev Physiol 62:755-778.

Sola M, Kneussel M, Heck IS, Betz H, Weissenhorn W (2001) X-ray crystal structure of the trimeric N-terminal domain of gephyrin. J Biol Chem 276:25294-25301.

Tai AW, Chuang JZ, Bode C, Wolfrum U, Sung CH (1999) Rhodopsin's carboxy-terminal cytoplasmic tail acts as a membrane receptor for cytoplasmic dynein by binding to the dynein light chain tctex-1. Cell 97:877-887.

Tochio H, Ohki S, Zhang Q LiM, Zhang M (1998) Solution structure of a protein inhibitor of neuronal nitric oxide synthase. Nat Struct Biol 5:965-969.

Todd AJ, Watt C, Spike RC, Sieghart W (1996) Colocalization of GABA, glycine, and their receptors at synapses in the rat spinal cord. J Neurosci 16:974-982.

Triller A, Sotelo C (1997) The central neuron. In: Grenfield's neuropathology, Ed 6 (Graham DI, Lantos PL, eds), pp 3-31. London: Arnold.

Triller A, Cluzeaud F, Pfeiffer F, Betz H, Korn H (1985) Distribution of glycine receptors at central synapses: an immunoelectron microscopy study. J Cell Biol 101:683-688.

Triller A, Cluzeaud F, Korn H (1987) Gamma-aminobutyric acidcontaining terminals can be apposed to glycine receptors at central synapses. J Cell Biol 104:947-956.

Walikonis RS, Jensen ON, Mann M, Provance Jr DW, Mercer JA, Kennedy MB (2000) Identification of proteins in the postsynaptic density fraction by mass spectrometry. J Neurosci 20:4069-4080.

Wu X, Jung G, Hammer III JA (2000) Functions of unconventional myosins. Curr Opin Cell Biol 12:42-51.

Xiang S, Nichols J, Rajagopalan KV, Schindelin H (2001) The crystal structure of Escherichia coli MoeA and its relationship to the multifunctional protein gephyrin. Structure 9:299-310.

Ziff EB (1997) Enlightening the postsynaptic density. Neuron 19:11631174. 